\section{Qualidade de água em sistemas de reservação e distribuição predial na cidade do Rio de Janeiro}

\author{
Carlos Alberto Silva Miranda*
}

Teofilo Carlos do Nascimento Monteiro*
* Departamento de Saneamento e Saúde Ambiental da Escola Nacional de Saúde Pública - Fundaçâo Oswaldo Cruz
Foi realizada uma avaliação dos resultados de boletins de análise bacteriológica fornecidos pela Fundação Estadual de Engenharia do Meio Ambiente e pela Escola Nacional de Saúde Pública nos anos de 1985 e 1986, suscitada pelo mau estado de conservação e de limpeza dos sistemas de distribuiçâo e reservação de água de considerável número de prédios na Cidade do Rio de Janeiro.

O trabalho visa mostrar a necessidade de uma pesquisa mais detalhada a fim de fornecer parâmetros que alertem as autoridades municipais quanto à necessidade de um regulamento que obrigue a limpeza $e$ desinfecção destes sistemas por ocasiāo do Habite-se e com periodicidade a ser determinada em prédios já habitados.

Recomenda-se, ainda, que a comprovação do serviço acompanhe laudo de análise por profissional habilitado.

\section{INTRODUÇÃO}

O presente trabalho tem como objetivo principal alertar as autoridades e órgãos competentes para a necessidade de um maior controle da qualidade bacteriológica das águas dos sistemas prediais da cidade do Rio de Janeiro.

Muito embora a água que abastece cerca de $80 \%$ da cidade do Rio de J an eiro seja proveniente da Estação de Tratamento de Água do Guandu (CEDAE) e os $20 \%$ restantes de outras fontes (CEDAE), que é de qualidade bacteriológica considerada boa, qual seja, dentro dos limites estabelecidos pelos padróes de potabilidade (NB19 / Bsb 56/M.S.), a preocupação que nos levou a elaborar este trabalho não foi o questionamento da qualidade da água fomecida pela CEDAE, mas sim, do seu ponto de entrada nos sistemas prediais e/ou residenciais, envolvendo caixas d'água, cistemas e redes de distribuição até a saída nas torneiras, onde são usadas pelos consumidores.

Cabe, aqui neste tópico, lembrar que água potável além de obedecer às características de qualidade físicas, organolépticas e químicas, deverá obedecer às seguintes características bacteriológicas (1):

Cadernos de Saúde Pública, RJ, 5(3): 284-295, jul/set, 1989 
1. De todas as porções-padrão (volume de 10 $\mathrm{ml}$, quando a técnica de exame bacteriológico é do processo dos tubos múltịlos) de $10 \mathrm{ml}$ examinadas por ano, semestre ou mês naao mais de $10 \%$ deverão revelar a presença de germes do Grupo Coliforme, quando a técnica do exame bacteriológico for do processo pelos tubos múltiplos.

1.1. Eventualmente, 03 (três) ou mais de 05 (cinco) porções-padrão componentes de uma amostra-padrão, conjunto de 05 (cinco) porçōes-padrão de 10 ml cada uma, a serem examinadas na mesma ocasião e provenientes do mesmo frasco de amostra de água, se a técnica do exame bacteriológico for a do processo dos tubos múltiplos - e o volume de $100 \mathrm{ml}$ de água a ser examinada se a técnica empregada for a do processo da membrana filtrante, poderäo conter germes do grupo coliforme, desde que não ocorra o seguinte:

. em amostras consecutivas

- em mais de $5 \%$ do total de amostras examinadas

1.2. A técnica do exame bacteriológico será pelo processo de ensaio confirmatório, usando calro lactosado com verde-brilhante e bile a $2 \%$.

2. A média aritmética da densidade de coliformes de todas as amostras-padrão, examinadas por ano, semestre ou mês, não deve exceder a um por $100 \mathrm{ml}$ $(1: 100 \mathrm{ml})$, se a técnica do exame bacteriológico for a do processo da membrana filtrante.

2.1. Eventualmente, uma amostra-padrão pode apresentar até 04 (quatro) ou mais coliformes por 100 $\mathrm{ml}$ desde que não ocorra o seguinte:

. em amostras consecutivas

- em mais do que $10 \%$ das amostras examinadas

2.2. A técnica do exame bacteriológico será a do processo padräo, utilizando o meio M-Endo, quando a técnica como dito for a de membranas filtrantes.

3. Quando as amostras de água de sistemas de abastecimento público, após exame bacteriológico quer pelo processo dos tubos múltiplos, quer pelo processo da mernbrana filtrante, revelarem resultados desfavoráveis, novas amostras serão colhidas em dias consecutivos, nos mesmos pontos dos anteriores dentro do sistema, até que se demonstre que as providências tomadas fizeram cessar a anormalidade. Essas amostras consideradas extraordinárias não serão computadas no número mínimo de amostras estabelecidas na tabela I retirada dos padröes de potabilidade, que indica a freqüência mínima de amostragem para a verificação da característica de qualidade bacteriológica da água de sistema público por população total da localidade. 
TABELA 1

Freqüência mínima de amostragem para a verificação da característica de qualidade bacteriológica da água de sistema de abastecimento público por populaçâo total da localidade.

\begin{tabular}{|c|c|c|c|}
\hline \multicolumn{2}{|c|}{$\begin{array}{l}\text { PROCUCAO TOTAL } \\
\text { (habitantes) }\end{array}$} & \multirow{2}{*}{$\begin{array}{c}\text { NÜMERO MINIMO DE AMOSTRAS } \\
\text { COLHIDAS NA REDE DE } \\
\text { DISTRIBUICAO POR MES } \\
\frac{1}{2} \\
3 \\
4\end{array}$} & \multirow{2}{*}{ 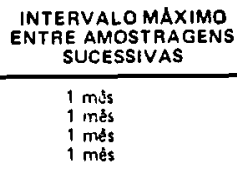 } \\
\hline $\begin{array}{r}5.001 \text { a } \\
10.001 \text { a } \\
15.001 \text { a }\end{array}$ & $\begin{array}{rr}5.000 \\
& 10.000 \\
15.000 \\
20.000\end{array}$ & & \\
\hline $\begin{array}{l}20.001 \text { a } \\
25.001 \text { a } \\
30.001 \text { a } \\
35.001 \\
40.001\end{array}$ & $\begin{array}{ll}25.000 \\
30.000 \\
35.000 \\
40.000 \\
45.000\end{array}$ & $\begin{array}{l}5 \\
6 \\
7 \\
8 \\
9\end{array}$ & $\begin{array}{l}2 \text { semanas } \\
2 \text { semands } \\
2 \text { seminits } \\
2 \text { semanas } \\
2 \text { semanas }\end{array}$ \\
\hline $\begin{array}{l}45.001 \\
50.001 \text { a } \\
55.001 \\
60.001 \text { a } \\
65.001 \\
70.001 \\
75.091 \\
80.001 \\
35.001 \\
90.001 \\
95.001\end{array}$ & $\begin{array}{r}50.000 \\
55.000 \\
60.000 \\
65.000 \\
70.000 \\
75.000 \\
80.000 \\
85.000 \\
90.000 \\
95.000 \\
100.000\end{array}$ & $\begin{array}{l}10 \\
11 \\
12 \\
13 \\
14 \\
15 \\
16 \\
17 \\
18 \\
19 \\
20\end{array}$ & $\begin{array}{l}4 \text { dias } \\
4 \text { dias } \\
4 \text { dias } \\
4 \text { dias } \\
4 \text { dias } \\
4 \text { dias } \\
4 \text { dias } \\
4 \text { dias } \\
4 \text { dias } \\
4 \text { dias } \\
4 \text { dias }\end{array}$ \\
\hline $\begin{array}{l}100.001 \\
120.001 \\
140.001 \\
160.001 \\
180.001 \\
200.001 \\
220.001 \\
240.001 \\
260.001 \\
280.001\end{array}$ & $\begin{array}{ll} & 120.000 \\
& 140.000 \\
& 160.000 \\
180.000 \\
& 200.000 \\
220.000 \\
240.000 \\
260.000 \\
280.000 \\
300.000\end{array}$ & $\begin{array}{l}21 \\
22 \\
23 \\
24 \\
25 \\
26 \\
27 \\
28 \\
29 \\
30\end{array}$ & $\begin{array}{l}2 \text { dias } \\
2 \text { diss } \\
2 \text { dias } \\
2 \text { dias } \\
2 \text { dias } \\
2 \text { dius } \\
2 \text { dias } \\
2 \text { dius } \\
2 \text { dius } \\
2 \text { dias }\end{array}$ \\
\hline $\begin{array}{l}300.001 \\
320.001 \\
340.001 \\
360.001 \\
380.001 \\
400.001 \\
420.001 \\
440.001 \\
460.001 \\
480.001 \\
500.001 \\
550.001 \\
600.001 \\
650.001 \\
700.001 \\
750.001 \\
800.001 \\
850.001 \\
900.001 \\
950.001\end{array}$ & $\begin{array}{ll} & 320.000 \\
& 340.000 \\
& 360.000 \\
\text { a } & 380.000 \\
\text { a } & 400.000 \\
& 420.000 \\
\text { a } & 440.000 \\
\text { a } & 460.000 \\
\text { a } & 480.000 \\
\text { a } & 500.000 \\
\text { a } & 550.000 \\
& 600.000 \\
\text { a } & 650.000 \\
\text { a } & 700.000 \\
\text { a } & 750.000 \\
\text { a } & 800.000 \\
\text { a } & 850.000 \\
\text { a } & 900.000 \\
\text { a } & 950.000 \\
\text { d } & 1.000 .000\end{array}$ & $\begin{array}{r}32 \\
34 \\
36 \\
38 \\
40 \\
12 \\
44 \\
10 \\
48 \\
50 \\
55 \\
60 \\
65 \\
70 \\
75 \\
80 \\
85 \\
90 \\
95 \\
100\end{array}$ & $\begin{array}{l}1 \text { dia } \\
1 \text { dia } \\
1 \text { dia } \\
1 \text { dij } \\
1 \text { dia } \\
1 \text { dia } \\
1 \text { dia } \\
1 \text { dad } \\
1 \text { dia } \\
1 \text { dio } \\
1 \text { dia } \\
1 \text { dia } \\
1 \text { dia } \\
1 \\
1 \text { dia } \\
1 \text { dia } \\
1 \\
1 \text { dia } \\
1 \\
1 \text { dia } \\
1 \text { did } \\
1 \text { dia } \\
1 \text { dia }\end{array}$ \\
\hline $\begin{array}{l}1.000 .001 \\
1.100 .001 \\
1.200001 \\
1.300 .001 \\
1.400 .001 \\
1.500 .001 \\
1.600 .001 \\
1.700 .001 \\
1.800 .001 \\
1.900 .001 \\
2.000 .001 \\
2.200 .001 \\
2.400 .001 \\
2.600 .001 \\
2.800 .001\end{array}$ & 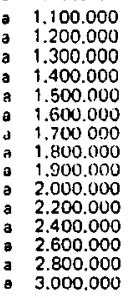 & $\begin{array}{l}110 \\
120 \\
130 \\
140 \\
150 \\
160 \\
110 \\
180 \\
190 \\
200 \\
220 \\
240 \\
200 \\
280 \\
300\end{array}$ & 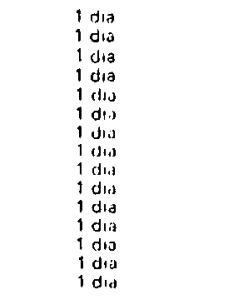 \\
\hline $\begin{array}{l}3.000 .001 \\
3.500 .001 \\
4.000 .001 \\
4.500 .001 \\
5.000 .001 \\
5.500 .001 \\
6.000 .001 \\
6.500 .001 \\
7.000 .001 \\
7.500 .001 \\
8.000 .001 \\
8500.01 \\
9.000 .001 \\
9.500 .001\end{array}$ & 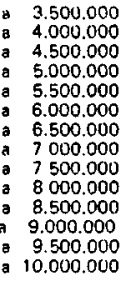 & $\begin{array}{l}350 \\
400 \\
450 \\
500 \\
550 \\
600 \\
650 \\
700 \\
750 \\
800 \\
850 \\
900 \\
950 \\
1.000\end{array}$ & $\begin{array}{l}1 \\
1 \\
1 \\
1 \text { dia } \\
1 \text { dia } \\
1 \text { dia } \\
11 \text { dia } \\
11 \text { dia } \\
1 \text { dia } \\
1 \text { did } \\
1 \text { dia } \\
1 \text { dia } \\
11 \text { dia } \\
11 \text { dia } \\
1 \text { dia } \\
1 \text { did }\end{array}$ \\
\hline $\begin{array}{l}10.000 .001 \\
11.000 .001\end{array}$ & $\begin{array}{ll}11.000 .000 \\
& 12000.000\end{array}$ & $\begin{array}{l}1.100 \\
1.200\end{array}$ & $\begin{array}{l}1 \text { dia } \\
1 \text { dia }\end{array}$ \\
\hline
\end{tabular}


4. A certificação de qualidade bacteriológica da água deverá ser feita:

. anualmente, quando se examinam até 05 (cinco) amostras mensais;

. semestralmente, quando se examinam de 06 (seis) a 20 (vinte) amostras mensais;

- mensalmente, quando se examinam mais de 20 (vinte) amostras mensais.

Cabe agora, observar que os dados da tabela são para amostras colhidas na rede de distribuição, enquanto que o que se pretende neste trabalho é alertar para uma necessidade de controle na frequência mínima de amostragem, em função da qualidade, no ponto final de uso do consumidor, após passar por cistemas, caixas d'água, de predial até tomeiras.

\section{METODOLOGIA}

Diante desta preocupação, surgiu-nos a idéia de realizar um levantamento de resultados dos boletins de análise de água feitos na Escola Nacional de Saúde Pública (ENSP-FIOCR UZ) e na Fundação Estadual de Engenharia do Meio Ambiente (FEEMA).

Cabe-nos esclarecer que essas análises não foram realizadas com finalidade de pesquisa, mas sim por solicitação de interessados que, ou desconfiavam da qualidade de sua água ou mantinham uma regularidade no controle da mesma.

An alisando esses resultados verificamos a necessidade de desenvolver um trabalho muito mais profundo e minucioso do que pretendido inicialmente. Assim sendo, este trabalho consiste apenas de uma advertência inicial, com vista a realização de uma investigação científica a nível de pesquisa que nos conduza a resultados que caracterizem melhor qualidade d'água da cidade, através de um programa de coleta e análise de amostras por Regiões Administrativas e distritos de água de forma que representem estatisticamente a realidade da qualidade de água consumida pela população da cidade do Rio de Janeiro.

$E$ nossa intenção, ainda, desenvolver uma sistemática de controle de qualidade de água em sistemas de reservação e distribuição predial de água, bem como, fornecer dados que obriguem uma periodicidade de análises de água em todos os prédios da Cidade do Rio de Janeiro.

\section{RESULTADOS}

\subsection{Apresentação e Interpretação}

A tabela aqui apresentada, é um resumo dos boletins de análises que conseguimos computar nos anos Cadernos de Saúde Pública, RJ, 5(3): 284-295, jul/set, 1989 
de 1985 e 1986, além de uns poucos de 1984. Nela estão descritos os endereços com os respectivos bairros, a data da coleta das amostras e o resultado bacteriológico, mostrando apenas se esses foram positivos ou negativos, sem indicar o NMP (número mais provável de coliformes).

O fato preocupante ao interpretar a tabela é que em cerca de 150 (cento e cinqüenta) boletins de análises, 30 (trinta) apresentaram resultados positivos, o que significa dizer que $20 \%$ do total das águas estavam contaminadas, o que é um dado bastante significativo, e que leva a necessidade de se pesquisar mais profundamente a razão deste índice que, por terem sido estas análises realizadas por solicitação de interessados, pode não condizer com a estatística real, pois este índice pode estar bem acima deste valor, principalmente em regiōes onde os prédios são mais antigos e onde a conservação e manutenção das instalações é precária.

Sendo o controle de qualidade da água nas redes de abastecimento de água um processo rotineiro que visa manter a boa qualidade da mesma, já estabelecido por normas e padrōes como citado antes, torna-se necessário estender este controle no interior de prédios a fim de que esta boa qualidade se mantenha até o ponto final de consumo.

Entendemos que esse controle deveria ser de responsabilidade da administração de cada prédio, e não da companhia distribuidora da água, que mantém o seu controle periódico na rede pública de abastecimento.

As análises realizadas nesta coletânea de resultados foram examinadas pelo processo do Tubos Múltiplos, tanto na Escola Nacional de Saúde Pública (Departamento de Saneamento e Saúde A mbiental), como na Fundaçāo Estadual de Engenharia do Meio Ambiente (FEEMA), de acordo com o método proposto pelo Standard Methods 15: Ed. (2)

\subsection{Discussāo}

Fato que muito freqüentemente ocorre é, diante da reclamação de consumidores, a administração de prédios contratar entidades que prestam serviços de qualidade de água, para analisar a água de determinado prédio. Isto ocorre porque o consumidor, leigo no assunto, só reclama se perceber algum odor, sabor ou cor estranha na sua água, ou seja, alterações nas características organolépticas.

Sabe-se, no entanto, que muitas vezes uma água, mesmo estando com suas características organolépticas em boas condições, a sua qualidade bacteriológica ao ser analisada se apresenta em condiçōes muito piores do que uma outra que possua características organolépticas ruins e qualidade bacteriológica melhor. 
TABELA 2

Resumo dos resultados de análises bacteriológicas em orédios da cidade do Rio de Janeiro.

\begin{tabular}{|c|c|c|c|}
\hline $\begin{array}{lll}R & U & A\end{array}$ & $B A I R R O$ & RESULTADO & DATA COLETA \\
\hline JARDIM BOTANICO & JARDIM BOTANICQ & + & 19.03 .84 \\
\hline CONECO VASCONCELOS, 186 & BANGU & + & 09.04 .84 \\
\hline VITOR MACRTUA, 3 & LAGOA & + & 11.04 .85 \\
\hline MARECHAL RONDON, 4 & MARACANÃ & + & 08.11 .84 \\
\hline OLIMPIO DA MOTA, 51 & IRAJA & - & 30.01 .85 \\
\hline NILO PEÇANHA, 50 & CENTRO & - & 06.02 .85 \\
\hline Av. DAS AMERICAS, Km 13,5 B1 5 & BARRA & - & 11.02 .85 \\
\hline FENINA DE ANDRADE, 29 & CACHAMBI & - & 13.02 .85 \\
\hline SANTA CLARA, 431 & COPACABANA & + & 14.02 .85 \\
\hline VISCONDE DE CARAVELAS, 98 & HUMAITA & - & 12.02 .85 \\
\hline Av. RIO BRANCO (EP.AV. CENTRAL) & CENTRO & - & 28.02 .85 \\
\hline LEOPOLDO MIGUEL & COPACABANA & + & 06.03 .85 \\
\hline Av. ATLANTICA, 1572 & COPACABANA & - & 06.03 .85 \\
\hline SETE DE SETEMBRO, 111 & CENTRO & - & 06.03 .85 \\
\hline Av.SERNAMBETIBA, 3600 & BARRA & - & 07.03 .85 \\
\hline SANTA CAROLINA, 7 & USINA & - & 07.03 .85 \\
\hline COSME VELHO, 318 & COSME VELHO & - & 14.03 .85 \\
\hline NILO PEÇANHA, 50 & CENTRO & - & 18.03 .85 \\
\hline SETE DE SETEMBRO,111 & CENTRO & - & 19.03 .85 \\
\hline PEDRO DE CARVALHO & LINS VASCONCELOS & - & 30.04 .85 \\
\hline SETE DE SETEMBRO & CENTRO & - & 28.05 .85 \\
\hline ALMIRANTE BARROSO, 63 & CENTRO & - & 30.05 .85 \\
\hline AQUARELO DO BRASIL, 333 & SATO .CONRADO & - & 20.06 .85 \\
\hline SETE DE SETEMBRO,111 & CENTRO & - & 13.06 .85 \\
\hline 28 DE SETEMBRO, 226 & VILA ISABEL & - & 02.07 .85 \\
\hline NILO PEÇANHA, 50 & CENTRO & - & 20.06 .85 \\
\hline MAL. JOFRE, 122 & GRAJAO & - & 18.07 .85 \\
\hline BUENOS AIRES, 90 & CENTRO & - & 02.07 .85 \\
\hline OSWALDO CRUZ & FLAMENGO & + & 29.07 .85 \\
\hline 13 DE MAIO, 47 & CENTRO & - & 07.05 .85 \\
\hline AV. MARACANÃ, 707 & MARACANÃ & - & 27.05 .85 \\
\hline EST. GAVEA, 707 & SÃO CONRADO & - & 08.05 .85 \\
\hline NICARAGUA, 635 & PENHA & - & 22.05 .85 \\
\hline LOCIO DE MENDGANGA, 25 & TIIUCA & - & 27.05 .85 \\
\hline JOLIO DE MOURA, 481 & BARRA & - & 03.06 .85 \\
\hline MARINO DA COSTA, 143 & ILHA & - & 03.06 .85 \\
\hline SILVA ROSA, 261 & MARIA DA GRAÇA & - & 10.06 .85 \\
\hline GARIBALDI, 145 & TIJUCA & - & 11.07 .85 \\
\hline FABIO DA LUZ,499 & MEIER & + & 04.07 .85 \\
\hline
\end{tabular}




\begin{tabular}{|c|c|c|c|}
\hline$R \quad U \quad A$ & $B A I R R O$ & RESULTADO & DATA COLETA \\
\hline RUA 1 COM RUA 34 & ITAIPUAÇU & + & 13.05 .85 \\
\hline PRAIA DE BOTAFOGO, 460 & BOTAFOGO & - & 14.05 .85 \\
\hline NILO PEÇAVHA, 50 & CENTRO & - & 17.07 .85 \\
\hline SAO FRANCISCO XAVIER & TIJUCA & - & 23.07 .85 \\
\hline 7 DE SETEMBRO, 111 & CENTRO & - & 21.08 .85 \\
\hline NILO PEÇANHA, 50 & CENTRO & - & 15.08 .85 \\
\hline GRAÇA ARANHA, 26 & CENTRO & - & 26.09 .85 \\
\hline PRES. WILSON, 228 & CENTRO & - & 26.09 .85 \\
\hline NILO PEÇANHA, 50 & CENTRO & - & 18.09 .85 \\
\hline NILO PEÇANHA, 50 & CENTRO & - & 16.10 .85 \\
\hline CARLOS DE VASCONCELOS, 73 & TIJUCA & + & 04.12 .85 \\
\hline NILO PEÇANHA, 50 & CENTRO & - & 10.12 .85 \\
\hline TONELERO, 242 & COPACABANA & - & 15.01 .86 \\
\hline VIEIRA SOUTO,1136 & IPANEMA & - & 15.01 .86 \\
\hline 7 DE SETEMBRO, 111 & CENTRO & - & 16.01 .86 \\
\hline Av.N.S. COPACABANA, 1335 & COPACABANA & + & 14.01 .86 \\
\hline NILO PEÇANHA, 50 & CENTRO & - & 17.02 .86 \\
\hline FERREIRA DE ANDRADE,29 & CACHAMB I & - & 18.02 .86 \\
\hline ROD.PET/TEREZ.KM 3,5 & PETROPOLIS & + & 12.02 .86 \\
\hline NILO PEÇANHA, 50 & CENTRO & - & 08.01 .86 \\
\hline BARÃO DE MESQUITA, 850 & GRAJAO & - & 23.01 .86 \\
\hline EST. PAU FERRO, 155 & JACAREPAGUA & + & 18.02 .86 \\
\hline VALPARAISO, 36 & TIJUCA & + & 30.06 .86 \\
\hline ABELARDO LOBO, 46 & LAGGA & - & 18.06 .86 \\
\hline SÃO CLEMENTE, 88 & BOTAFOGO & - & 24.06 .86 \\
\hline ARAOJO LEITĀO,607 & ENG. NOVO & + & 23.06 .86 \\
\hline SILVEIRA LOBO, 84 & CACHAMBI & + & 18.06 .86 \\
\hline NILO PEÇANHA, 50 & CENTRO & - & 10.06 .86 \\
\hline ALMIRANTE BARROSO, 63 & CENTRO & - & 29.05 .86 \\
\hline JORGE RUDGE, 44 & VILA ISABEL & + & 03.06 .86 \\
\hline SAOO CLENENTE, 88 & BOTAFOGO & + & 03.06 .86 \\
\hline PEDRO DE CARVALHO, 428 & LINS VASCONCELOS & - & 27.05 .86 \\
\hline BARÃO DE IFANEMA, 105 & IPANEMA & - & 22.05 .86 \\
\hline 7 DE SETEMBRO, 111 & CENTRO & - & 19.05 .86 \\
\hline CAMARAGIBE, 16 & TIJUCA & - & 15.05 .86 \\
\hline CONDE DE BONFIM, 425 & TIJUCA & - & 15.05 .86 \\
\hline EST. DO CAPENHA, 1431 & JACAREPAGUA & + & 13.05 .86 \\
\hline EST. DA GAVEA, 11 & GAVEA & - & 14.05 .86 \\
\hline BARZ̃O DE MESQUITA, 850 & TIJUCA & - & 23.04 .86 \\
\hline NILO PEÇANHA, 50 & CENTRO & - & 20.03 .86 \\
\hline PALHEIRAS, 32 & BOTAFOGO & - & 07.04 .86 \\
\hline 13 DE MAIO, 13 & CENTRO & - & 09.04 .86 \\
\hline
\end{tabular}




\begin{tabular}{|c|c|c|c|}
\hline $\begin{array}{lll}R & U & A\end{array}$ & $B A I R R(1)$ & RESULTADO & DATA COLETA. \\
\hline SAO SALVADOR, 111 & LARANJEIRAS & - & 10.07 .85 \\
\hline MENDES DE MORAIS, 805 & SAOO CONRADO & - & 19.08 .85 \\
\hline MARIA QUITERIA, 78 & IPANEMA & - & 31.07 .85 \\
\hline REDENTOR, 300 & IPANEMA & - & 26.09 .85 \\
\hline ERERE, 11 & COSME VELHO & + & 08.08 .85 \\
\hline NILO PEÇANHA, 50 & CENTRO & - & 13.08 .85 \\
\hline TONELERO, 315 & COPACABANA & - & 18.07 .85 \\
\hline EST. JACAREPAGUA, 7166 & JACAREPAGUA & - & 22.08 .85 \\
\hline GAGO COUTINHO,77 & LARANJEIRAS & - & 16.09 .85 \\
\hline BUENOS AIRES, 68 & CENTRO & - & 21.10 .85 \\
\hline MONTE ALEGRE & STA TEREZA & - & 19.09 .85 \\
\hline EST.VELHA DA PAVUNA, 4800 & INHAOMA & - & 07.10 .85 \\
\hline BOAVENTURA TOLOMEI,55 & PENHA & + & 12.12 .85 \\
\hline TIMOTEO DA COSTA, 815 & LEBLON & - & 04.12 .85 \\
\hline BOAVENTURA TOLOMEI,55 & PENHA & + & 06.01 .85 \\
\hline CONDE DE BONFIM, 1279 & LARANJEIRAS & - & 19.12 .85 \\
\hline LARANJEIRAS, 99 & LARANJEIRAS & - & 16.12 .85 \\
\hline CUSTÓDIO SERRÃO,58 & LAGOA & - & 04.12 .85 \\
\hline DELGADO DE CARVALHO, 44 & TIJUCA & - & 29.01 .85 \\
\hline BORDA DO MATO, 243 & GRAJAO & - & 31.02 .85 \\
\hline 7 DE SETEMBRO,111 & CENTRO & + & 05.02 .85 \\
\hline VISCONDE DE PIRAJA, 459 & IPANEMA & - & 31.01 .85 \\
\hline HONORIO DE BARROS, 27 & FLAMENGO & - & 11.02 .85 \\
\hline DELGADO DE CARVALHO, 44 & TIJUCA & - & 07.02 .85 \\
\hline OSWALDO CRUZ, 73 & FLAMENGO & - & 20.02 .85 \\
\hline DONA MARIANA, 100 & BOTAFOGO & + & 25.02 .85 \\
\hline TONELERO, 242 & COPACABANA & + & 14.02 .85 \\
\hline AV. SUBURBANA, 7287 & ABOLIÇన̃O & - & 25.02 .85 \\
\hline AV.PRES, VARGAS, 529 & CENTRO & - & 28.02 .85 \\
\hline VISCONDE SILVA, 154 & BOTAFOGO & - & 13.02 .85 \\
\hline POVINA CAVAICANTI & SÃO CONRADO & + & 11.04 .85 \\
\hline BARATA RIBEIRO, 12 & COPACABANA & - & 12.03 .85 \\
\hline HADOCK LOBO, 39 & ESTACIO & - & 14.03 .85 \\
\hline CAPITAOO SALOMIX̃O, 14 & BOTAFOGO & - & 11.03 .85 \\
\hline EST.DO GALEĀO,2029 & ILHA & - & 26.03 .85 \\
\hline FIG. MAGALHÃES, 663 & COPACABANA & - & 20.03 .85 \\
\hline CAPITÃO NENEZES, 1606 & JACAREPAGUA & - & 27.03 .85 \\
\hline COMENDADOR PINTO, 154 & CAMPINHO & - & 25.03 .85 \\
\hline Dr. LEAL, 550 & ENG. DENTRO & - & 20.03 .85 \\
\hline CASTRO BARBOSA, 65 & GRAJAO & - & 27.03 .85 \\
\hline MARINO DA COSTA & ILHA & + & 29.04 .85 \\
\hline OSWALDO CRUZ,73 & FLAMENGO & + & 15.05 .85 \\
\hline ALM, SADOCK DE SA & LAGOA & - & 16.04 .85 \\
\hline
\end{tabular}




\begin{tabular}{|c|c|c|c|c|}
\hline$u$ & A & $B A I R R O$ & RESULTADO & DATA COLETA \\
\hline \multicolumn{2}{|c|}{ PEDRO DE CARVALHO,691 } & MEIER & - & 02.04 .86 \\
\hline \multicolumn{2}{|c|}{ CARLOS DE VASCONCELOS.73 } & TIJUCA & $=$ & 02.04 .86 \\
\hline \multicolumn{2}{|c|}{ COMENDADOR TELES, 2393} & VILAR DOS TELES & + & 17.03 .86 \\
\hline \multicolumn{2}{|l|}{ URUGUAI, 135} & ANDARAI & - & 20.03 .86 \\
\hline \multirow{2}{*}{\multicolumn{2}{|c|}{$\begin{array}{l}\text { VICE.GOV. RUBENS BERARDO, } 175 \\
\text { NILO PEÇANHA, } 50\end{array}$}} & GAVEA_ & - & 20.03 .86 \\
\hline & & CENTRO & - & 06.03 .86 \\
\hline \multicolumn{2}{|c|}{ PADRE ILDEFONSO PENALSA, 45} & TODOS OS SANTOS & - & 27.02 .86 \\
\hline \multicolumn{2}{|c|}{ Av. ATLANTICA, 1572} & COPACABANA & - & 04.06 .86 \\
\hline \multicolumn{2}{|c|}{ CAROLINA SANTOS, 48} & MEIER & - & 24.06 .86 \\
\hline \multicolumn{2}{|c|}{ ALMIRANTE BARROSO, 52} & CENTRO & $=$ & 13.05 .86 \\
\hline \multicolumn{2}{|c|}{ ADOLFO PORTO, 255} & ILHA DO GOV. & - & 17.06 .86 \\
\hline \multicolumn{2}{|l|}{ SAO SALVADOR, 14} & SAO SALVADOR & - & 21.05 .86 \\
\hline \multicolumn{2}{|l|}{ NILO PEÇANHA, 50} & CENTRO & - & 08.05 .86 \\
\hline \multicolumn{2}{|c|}{ ALM. ALVVARO ALBERTO, 180} & SÃO CONRADO & - & 22.05 .86 \\
\hline \multicolumn{2}{|c|}{ RAINHA ELIZABETH, 499} & COPACABANA & - & 22.05 .86 \\
\hline \multicolumn{2}{|c|}{ GONZAGA BASTOS, 20} & VILA ISABEL & - & 22.05 .86 \\
\hline \multicolumn{2}{|l|}{ PRES.VARGAS, 529} & CENTRO & - & 22.05 .86 \\
\hline \multicolumn{2}{|l|}{ STA CRUZ, 833} & REALENGO & - & 15.04 .86 \\
\hline \multicolumn{2}{|c|}{ LOPES DA CRUZ, 167} & MEIER & - & 08.05 .86 \\
\hline \multicolumn{2}{|c|}{ DANIEL CARNEIRO, 92} & ENG. DENTRO & - & 06.04 .86 \\
\hline \multicolumn{2}{|c|}{ BARÃO DA TORRE, 431} & IPANEMA & - & 03.04 .86 \\
\hline \multicolumn{2}{|c|}{ JOAQUIM LOPES DE MACEDO, 15} & CAXIAS & - & 08.01 .86 \\
\hline \multicolumn{2}{|l|}{ HADOCK LOBO, 53} & TIJUCA & - & 27.02 .86 \\
\hline \multicolumn{2}{|c|}{ MORAIS E SILVA, 29} & MARACANA & + & 19.02 .86 \\
\hline
\end{tabular}

Este fato conduz a um freqüente erro de o consumidor estar consumindo uma água de má qualidade pensando que está boa, ou uma boa pensando que está ruim e muitas vezes acusa a companhia distribuidora como responsável pela má qualidade. Daí surge a necessidade também de que, em toda e qualquer análise que se fizer em al gum prédio ou mesmo casas, se faça também coleta de amostras nos pontos de entrada da água no sistema antes de chegar nas cistemas para uma comparação real da qualidade das águas.

As formas de contaminação de um sistema predial são diversas. As cisternas de caixas d'água são pontos em potencial de contaminação já que estas apresentam

Cademos de Saúde Pública, RJ, 5(3): 284-295, jul/set, 1989 
uma superfície livre e ainda, não são completamente vedadas, estando freqüentemente expostas a vários pontos de contaminaçăo (3).

Um sistema que apresenta um menor risco potencial de contaminação na distribuição predial é o sistema direto de suprimento, que não utiliza reservatórios, onde a água é aduzida diretamente às peças de consumo. Esse sistema não é adotado frequientemente pelo seu alto custo de implantação, onde as tubulaçōes de distribuição possuem diâmetros e pressōes superiores em comparação com os adotados nos sistemas com reservatórios prediais, onde o risco de contaminação é bastante superior e merecedor de maior controle de qualidade.

Tendo em vista o período de chuvas com enchentes no Rio de Janeiro, em fevereiro deste ano podemos, com certeza, concluir que o quadro é bem mais agravante agora, visto que diversos prédios tiveram suas cistemas inundadas com as águas da enchente e em muitos casos os responsáveis pela administração dos prédios não tomam nenhuma providência ou em alguns casos a tomam de forma incorreta, como por exemplo, apenas limpando as cistemas e não desinfetando, ou usando quantidades erradas de desinfetante, o que pode ser de um risco muito alto para população habitante desses prédios.

Cabe então, nessa hora, a necessidade de além de medidas imediatas de controle por parte de autoridades municipais, estaduais, federais e profissionais sanitaristas, uma pesquisa de avaliação da qualidade da água consumida no Rio de Janeiro já que, se antes o quadro já alarmava, agora certamente está pior.

\section{CONCLUSÃO E PROPOSIÇÃO}

Segundo H. J. Ongerth (4) os responsáveis das empresas de abastecimento de águas e os responsáveis pela qualidade destas não deveriam recorrer só a cloração como solução universal dos problemas de contaminação. A cloração deve ser empregada para resolver problemas de qualidade de água causados pelos coliformes e outros fatores biológicos que não se possa resolver de outra forma uma vez que se tenha efetuado todos os esforços razoáveis para eliminar a causa básica do problema.

Não se deve considerar que a cloração deve ser um substituto de um programa ativo do controle das interconexōes, nem deverá empregá-la para mascarar outros defeitos como substitutivo para evitar a penetração da turbidez e matéria orgânica no sistema de distribuição. Naqueles casos que as análises de laboratório revelam que a água do sistema de distribuição está contaminada, é necessário realizar-se investi gações para se detectar a causa e adotar medidas corretivas. 
Considerando-se que na Cidade do Rio de Janeiro, o sistema de abastecimento predial é todo ele com o uso de reservatórios, o risco de contaminação é relativamente alto, tomando-se necessário um controle mais rígido de qualidade de água no interior dos prédios.

Como sugestão inicial, pois este trabalho, como dito anteriormente, não encerra o assunto mas, simplesmente, inicia-se, propomos uma sistemática de investigação para o controle dos sistemas prediais, com os seguintes passos:

1. Todos os novos prédios áa Cidade do Rio de Janeiro, por ocasião do Habite-se, deverão apresentar um certificado de comprovação de boa qualidade da água, fornecida por profissional credenciado.

2. Todos os prédios da Cidade do Rio de J an eiro já habitados deverão manter um controle de qualidade de água através de análises bactericlógicas periódicas num prazo de 06 (seis) meses.

- Devido a dificuldade por parte dos governos em controlar uma exigência deste tipo, sugerimos uma campanha de conscientização sanitária junto à população para que a mesma possa controlar a qualidade da água através da verifícação do prazo de validade dos certificados, que deverão ser afixados em local acessível a todos os moradores.

3. Os certificados de boa qualidade da água deverāo ser formecidos por profissionais habilitados e que obedeçam à seguinte sistemática de investigação:

3.1. Perícia de todo sistema de reservação e distribuição predial.

3.2. Verificar se existem reservatóros que permanecem com água estocada como reserva potencial por tempo demasiadamente longo, a fim de orientar o operador como trabalhar melhor no revezamento dos reservatórios.

3.3 Coletar amostra de água em ponto antes da entrada no sistema predial.

3.4. Coletar amostras de água em todos os pontos de reservação dos prédios.

3.5. Coletar amostras de água em todos os pontos de distribuição que foram julgados suspeitos na perícia.

3.6. Análise das amostras de água de acordo com método proposto pelo Standard Methods.

3.7. No caso da verificação de contaminação da água, fazer nova coleta e novo exame das amostras, após tratamento efetuado.

3.8. Emissão de certificado de boa qualidade de água que deverá ser tixado como descrito anteriormente.

Cademos de Saúde Pública, RJ, 5(3): 284-295, jul/set, 1989 
An assessment of the results of the bacteriological tests, supplied by Fundaçâo Estadual de Engenharia do Meio Ambiente (FEEMA) and by Escola Nacional de Saúde Pública during the years of 1985 and 1986. was performed due to the bad conditions of conservation and cleaning of the water distribution and reservoir systems of a great number of buildings in Rio de Janeiro.

This paper shows the necessity for further investigations in order to clarify the authorities about the need for strict regulations for cleaning and desinfections of these systems when legal permission for building occupation is granted. These regulations should also determine the periodicity of the cleanings and the desinfections. It is also advisable that the service certificate be conducted through a legal analysis performed by a qualified professional.

\section{AGRADECIMENTOS}

Os autores são gratos a Dr: DOVIS ALVIM da Fundação Estadual de Engenharia do Meio Ambiente pela colaboração prestada no fornecimento de dados substanciais para a execução deste trabalho. Ao Dr. SZACHNA ELIASZ CYNAMON agradecem pelo apoio e incentivo que vem dando aos Trabalhos de Pesquisa.

\section{REFERÊNCIAS BIBLIOGRÁFICAS}

1. MINISTÉRIO DA SAÚDE. Padröes de Potabilidade - portaria n: 56/Bsb - NB 19/M. S., 1977.

2. AMERICAN PUBLIC HEALTH ASSOCIATION. Standard Methods for Examination of Water and Waste Water, 15th Ed., 1981.

3. CYNÄMON, S. E. Apostilas da Escola Nacional de Saúde Pública - Fundação Oswaldo Cruz.

4. AMERICAN WATER WORKS ASSOCIATION. Water Quality Treatment, Inc. New York, 1975. 